
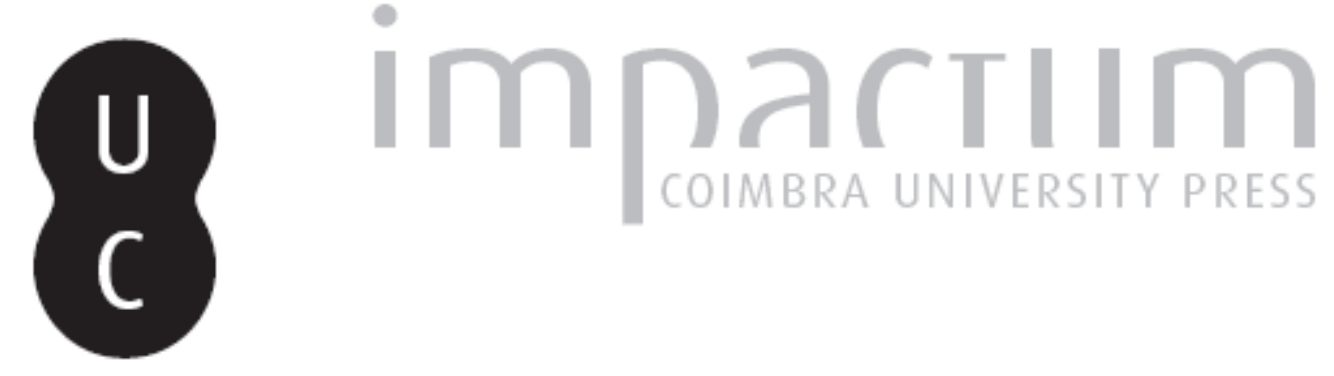

\title{
Prevenção da severidade na planície de inundação do rio Aquidauana na cidade de Aquidauana MS/Brasil: ações com a comunidade local
}

Autor(es): $\quad$ Anunciação, Vicentina Socorro da; Neto, João Lima Sant Anna

Publicado por: Imprensa da Universidade de Coimbra

URL

persistente:

URI:http://hdl.handle.net/10316.2/44211

DOI:

DOI:https://doi.org/10.14195/1647-7723_25-2_11

Accessed : $\quad$ 26-Apr-2023 12:38:47

A navegação consulta e descarregamento dos títulos inseridos nas Bibliotecas Digitais UC Digitalis, UC Pombalina e UC Impactum, pressupõem a aceitação plena e sem reservas dos Termos e Condições de Uso destas Bibliotecas Digitais, disponíveis em https://digitalis.uc.pt/pt-pt/termos.

Conforme exposto nos referidos Termos e Condições de Uso, o descarregamento de títulos de acesso restrito requer uma licença válida de autorização devendo o utilizador aceder ao(s) documento(s) a partir de um endereço de IP da instituição detentora da supramencionada licença.

Ao utilizador é apenas permitido o descarregamento para uso pessoal, pelo que o emprego do(s) título(s) descarregado(s) para outro fim, designadamente comercial, carece de autorização do respetivo autor ou editor da obra.

Na medida em que todas as obras da UC Digitalis se encontram protegidas pelo Código do Direito de Autor e Direitos Conexos e demais legislação aplicável, toda a cópia, parcial ou total, deste documento, nos casos em que é legalmente admitida, deverá conter ou fazer-se acompanhar por este aviso.

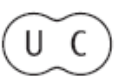




\title{
PREVENÇÃO DA SEVERIDADE NA PLANÍCIE DE INUNDAÇÃO DO RIO AQUIDAUANA NA CIDADE DE AQUIDAUANA MS/BRASIL: AÇÕES COM A COMUNIDADE LOCAL*
}

\section{PREVENTION OF SEVERE EVENTS ON THE AQUIDAUANA RIVER FLOODPLAIN IN THE CITY OF QUIDAUANA MS/BRAZIL: ACTIONS WITH THE LOCAL COMMUNITY}

Vicentina Socorro da Anunciação Universidade Federal de Mato Grosso do Sul Câmpus Aquidauana (Brasil) ORCID 0000-0001-8571-5109 vique56@hotmail.com

João Lima Sant `Anna Neto Universidade Estadual Paulista Campus de Presidente Prudente (Brasil) ORCID 0000-0003-0648-255X jlsn57@uol.com.br

\begin{abstract}
RESUMO
A bacia do rio Aquidauana abrange uma área de aproximadamente $21.373,85 \mathrm{Km}^{2}$, envolve 16 municípios no Estado de Mato Grosso do Sul-Brasil e apresenta três unidades fisiográficas: Planalto Maracaju-Campo Grande, Depressão Pantaneira, Planície do Pantanal Sul-Mato-Grossense, abrangendo parte dos biomas Cerrado e Pantanal. Frente ao processo de transformação que redefine a produção e a função do espaço local, o presente artigo busca compreender como se dá a relação da sociedade com a sua produção, a geografia, a escola e a práxis socioambiental.
\end{abstract}

Palavras-chave: Severidade, espaço, representação, sociedade, ensino.

\section{ABSTRACT}

The hydrographic basin of the River Aquidauana covers an area of approximately 21,373.85 $\mathrm{km}^{2}$ involving 16 municipalities in the state of Mato Grosso do Sul, Brazil. It has three physiographic units: Marazion-Campo Grande Plateau, Pantanal Depression, South Mato Grosso Pantanal Plain, covering part of the Cerrado and Pantanal biomes. Given the transformation process that redefines the production and function of the local area, this article aims to understand the society's relationship with its production, geography, schools and socio-environmental practice.

Keywords: Severity, space, representation, society, education.

\footnotetext{
* O texto deste artigo corresponde a uma comunicação apresentada no IV Congresso Internacional de Riscos, tendo sido submetido em 15-05-2017, sujeito a revisão por pares a 22-09-2017 e aceite para publicação em 19-03-2018. Este artigo é parte integrante da Revista Territorium, $n .{ }^{\circ} 25$ (II), 2018, ${ }^{\circ}$ RIscos, ISSN: 0872-8941.
} 


\section{Introdução}

Importantes transformações políticas, econômicas, sociais e ambientais têm influenciado direta ou indiretamente todos os espaços. Assim, observa-se que o mundo contemporâneo coloca fundamentalmente desafios à humanidade e inerente a isso a toda a população, sobretudo à que se encontra em faixa etária escolar.

Dessa forma, a comunidade científica (Rebelo,1997, 2003, 2010; Lourenço,1999, 2014; Nunes, Lourenço, Pinho, Bento-Gonçalves, Vieira, 2013), promoveu congressos e seminários específicos como o $6^{\text {th }}$ International Conference on Flood Management, realizado em setembro de 2014 na cidade de São Paulo, Brasil, com o tema central "Inundações em um ambiente de mudança", e o ocorrido na cidade de Guimarães, Portugal, em novembro de 2014, III Congresso Internacional de Riscos tendo como temática principal "Multidimensão e territórios de risco". Durante os dois eventos foram debatidas questões que possam vir de encontro ao anseio da sociedade e dos órgãos responsáveis pela defesa e bem-estar da população, visto que a problemática tem atingindo de forma expressiva, sobretudo, os espaços urbanos.

A geografia da cotidianidade instiga nas pessoas que estão inseridas, ou não, numa instituição de ensino, um sistema de percepção do espaço vivido como manifestação do meio social e questões conceituais, procedimentais e atitudinais à conceção, apropriação e entendimento do espaço geográfico, consolidando circunstâncias cognitivas e afetivas na organização espacial.

A ciência geográfica exerce o relevante oficio de dissecar e abordar as relações sociais que se dão no espaço. Assim, possibilita uma vertente de busca da compreensão das variáveis envolvidas nas transformações da realidade sócio espacial e de pensar a ação e o futuro que a envolve, pois em conformidade com Santos (1979), há uma organização social, um arranjo do espaço, de acordo com os interesses e necessidades de cada grupo.

Dessa forma, o espaço traz na sua essência uma sincronia de fisionomias que evidenciam elos sociais pretéritos e presentes, apresentando formas e funções constituídas historicamente, fruto da dinâmica sócio espacial. De acordo com (Santos 1979, p. 80)

"Seria impossível pensar em evolução do espaço se o tempo não tivesse existência no tempo histórico, [...] a sociedade evolui no tempo e no espaço. 0 espaço é o resultado dessa associação que se desfaz e se renova continuamente, entre uma sociedade em movimento permanente e uma paisagem em evolução permanente. [...] Somente a partir da unidade do espaço e do tempo, das formas e do seu conteúdo, é que se podem interpretar as diversas modalidades de organização espacial".
A partir desta epistemologia procura-se compreender como se dá a relação da sociedade com o seu cotidiano e a fluidez da água, relacionando com as práticas na produção do espaço no baixo curso da Bacia do Rio Aquidauana, a geografia, a escola e a práxis socioambiental.

Como é advertido pela geógrafa Seabra (2001) “[...] o cotidiano pode ser visto como o lugar do embate entre o concebido e o vivido", justifica-se a tarefa de promover a conscientização da sociedade para com este espaço, entendendo os problemas, as potencialidades, os conflitos, tornando os cidadãos conscientes. Fazse necessário analisar os processos e as formas que os agentes sociais imprimem na área, construindo o conhecimento sobre os conceitos essenciais como clima, tempo, bacia hidrográfica, legislações, códigos florestais, políticas públicas, riscos, conclamando gestores de toda área de abrangência e estabelendo ações conjuntas, uma vez que para os problemas ambientais não existem fronteiras geopolíticas.

A bacia do rio Aquidauana (fig. 1), abrange uma área de $21.373,85 \mathrm{Km}^{2}$, envolvendo 16 municípios do estado de Mato Grosso do Sul, com o alto curso no município de São Gabriel do Oeste, ao norte do estado de Mato Grosso do Sul; o médio curso na porção central: Corguinho, Rochedo, Terenos e Dois Irmãos do Buriti; e o baixo curso na orientação Centro-Oeste e Noroeste: Aquidauana, Anastácio e Miranda. Insere-se na divisão das bacias do Rio Paraguai e Paraná, e possui a cabeça de drenagem formada no Planalto do Maracaju-Campo Grande. O canal corta a região central do estado de Mato Grosso do Sul e segue na orientação Centro-Oeste e Noroeste, onde seu baixo curso se inicia na Depressão Pantaneira, desaguando na Planície do Pantanal Sul-MatoGrossense, abrangendo várias regiões morfoclimáticas de importância fitogeográfica. As atividades econômicas preponderantes são a agricultura, produção de carne bovina, atividade turística e industrial (laticínios, frigoríficos). Além disso, o manancial hídrico é disposto para o abastecimento público de água na cidade de Aquidauana na área central da bacia.

Estas particularidades em processo de transformação definem a produção e a função do espaço local, sedimentando na região (re)arranjos na perspectiva de competitividade da regionalização do espaço mundial frente ao processo de globalização, fazendo convergir para este território um palco depositário das ações e dos fenômenos globais e locais.

Neste espaço os objetos nascem com uma vocação mercantil, transformando-se de forma dinâmica, articulando materialidade e ação humana e gradativamente contribuindo para o avanço da vulnerabilidade socio ambiental. Daí resulta a maior repercussão socioespacial dos eventos, sobretudo os decorrentes de hazards climáticos que se processam no 


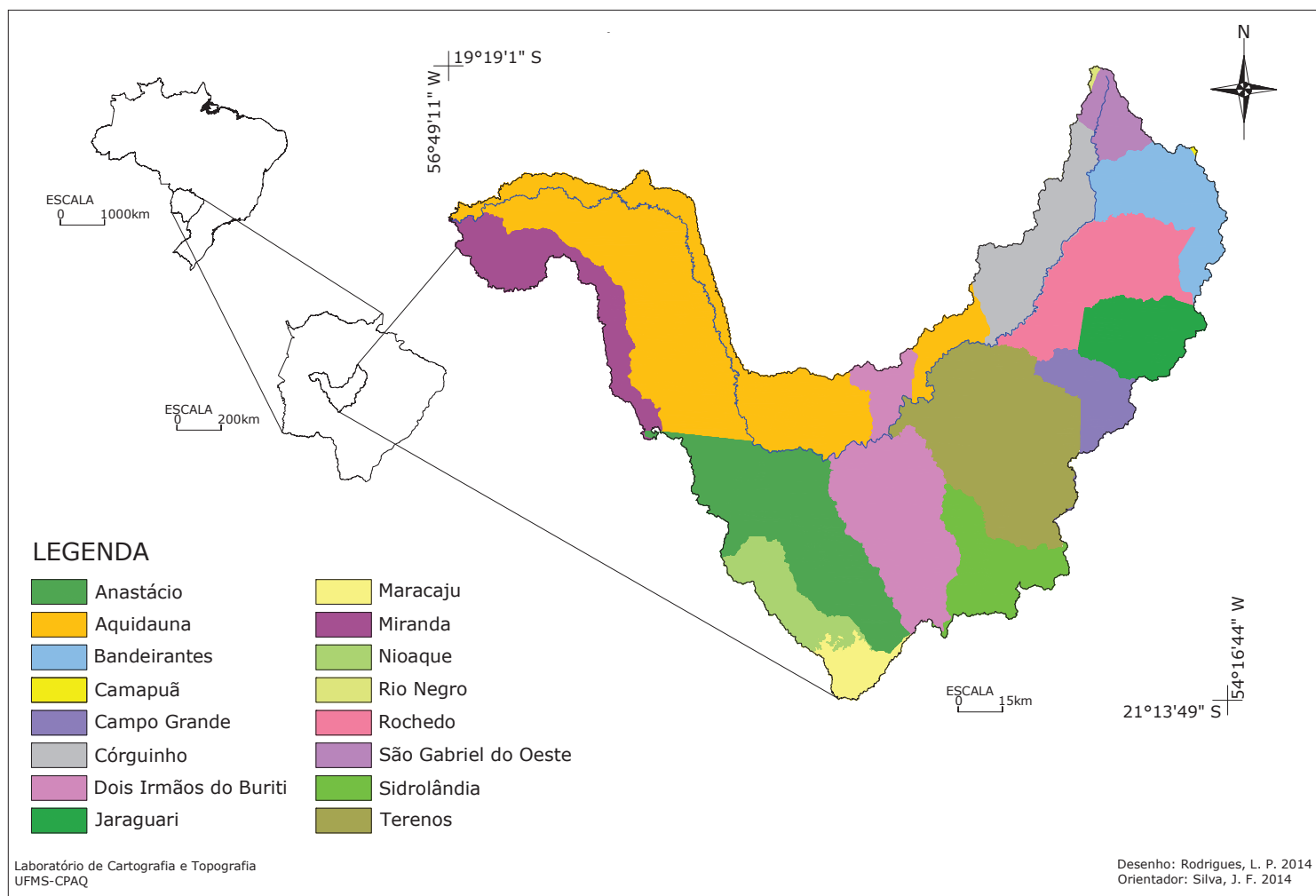

Fig. 1 - Localização da área (Fonte: Laboratório de Topografia e Cartografia, UFMS/CPAQ 2015).

Fig. 1 - Location of the area (Source: Topography and Cartography Laboratory, UFMS / CPAQ2015).

espaço urbano da cidade de Aquidauana. Assim, "O risco hidrológico, mais concretamente o risco de inundação, foi sempre muito grande e o homem foi sendo obrigado a tomar as suas precauções”(Rebelo, 2010, p.87).

De acordo com Kaercher, 2003, é preciso entender como e por que os seres humanos modificam os espaços que habitam, conforme as relações que estabelecem entre si. Fato que vem ratificar a necessidade de "melhor consciencialização dos riscos e melhor perceção do perigo" (Lourenço, 2014, p. 70).

Partindo da reflexão sobre a natureza e a produção do espaço, o presente estudo lança um olhar sobre a apropriação deste espaço pela sociedade, os impactos socioambientais, as implicações sócio espaciais, através do pensar e do fazer geográfico na universidade, na escola e na própria sociedade.

\section{A geografia como instrumento de análise e prevenção de riscos}

A geografia escolar torna possível a compreensão da complexidade social e espacial com a concretude e a singularidade do cotidiano no lugar que apresenta caráter geográfico, social, histórico e real concretos e tangíveis. Nessa perspectiva, são considerados os aspectos do presente e os precedentes históricos na apreensão do espaço vivido, pois, de acordo com os Parâmetros Curriculares Nacionais (1998, p.25) “[...] a geografia é uma área do conhecimento comprometida em tornar o mundo compreensível aos alunos, explicável e passivel de transformações".

A sociedade, em cada momento histórico, concebe o espaço materializando nele "os sistemas de objetos" resultantes do trabalho humano, para que "os sistemas de ações” possam ser desenvolvidos. Como são indissociáveis e cumulativos, pois um depende do outro, geram novos objetos e novas ações. Assim o espaço está permanentemente em construção, sendo produto das relações humanas e das relações dos homens com o meio. Assim, a aprendizagem espacial voltada para a compreensão das formas pelas quais a sociedade organiza seu espaço, deve ocorrer em outros meios, na escola, dando ênfase às as construções e reconstruções espaciais, no trabalho pedagógico geográfico.

Como dizia o grande pensador Freire (1996), "Ensinar exige a convicção de que a mudança é possível". Isso torna-se uma fonte para imergir na realidade local com a temática de riscos e entender sua história, a sua cotidianidade e a sua geografia, para romper os dilemas. Dessa forma, se consolida o processo de pensar, refletir, duvidar, contrapor sobre os aspectos sui generis, consubstanciado em todos os municípios envolvidos na 
área de abrangência, buscando uma ética de vida que se compromete na superação de atitudes e de ações que potencializam os impactos negativos nesse espaço, conclamando a responsabilidade social a quebrar a hegemonia predominante.

Segundo Callai (2003) "A Geografia que o aluno estuda deve permitir que ele se perceba como participante do espaço que estuda, onde os fenômenos que ali ocorrem são resultados da vida e do trabalho dos homens e estão inseridos num processo de desenvolvimento".

A partir da submersão na experiência vivida, como enfatiza Bondía (2002), "a experiência é o que nos passa, o que nos acontece, o que nos toca.... a experiência e o saber que dela deriva são o que nos permite apropriarnos de nossa própria vida", procura-se na educação geográfica e na climatologia geográfica razões para compartilhar a preleção temática.

Dessa forma, partiu-se do princípio dialógico por meio da pesquisa-ação, Tripp (2005), visto a necessidade de discutir, de forma participativa, a produção de conhecimento mediado pela participação e empoderamento dos sujeitos direta e indiretamente envolvidos com os episódios de inundação e na construção do saber, possibilitando aos participantes a reflexão coletiva de forma crítica sobre suas próprias práticas, conduzindo-os às mudanças de atitude.

$\mathrm{Na}$ pesquisa-ação não há dissociação entre sujeito e objeto de estudo, portanto, se configura como um processo de aprendizagem para todos os agentes sociais envolvidos na investigação.

A interação com os atores sociais torna-se necessária para discutir e avaliar conjuntamente as experiências e as abordagens planejadas e produzir de forma conjunta o percurso formativo. Assim, despertar o interesse para questões que minimizem as consequências dos desastres naturais aos quais a população da cidade de Aquidauana está exposta e auxiliar no processo de recuperação após calamidades como no caso das inundações, modelando uma nova representação socioespacial, no baixo curso do rio Aquidauana, e identificar mudanças de atitudes e comportamentos para com o lugar de vivência cotidiana.

Para conhecer a realidade e a dimensão do desafio, deve-se conclamar a responsabilidade social, romper a supremacia preeminente, agir com lisura e honestidade perante o "risco" a partir do foco das lentes da ciência geográfica. Um dos vieses de análise fundamenta-se na concepção da Geografia do Clima, considerando que os contrastes socioespaciais gerados pelas alteridades sociais são fulcrais na apreensão do fenômeno climático.

Dessa forma, na Climatologia Geográfica e a sua conceituação da Geografia do Clima, Sant anna Neto (2008), procurou-se o amparo para as reflexões teóricas metodológicas e na construção das atividades, versando sobre a temática dos riscos, uma vez que depreende o episódio climático inerente à sociedade e ao espaço, suplantando aspectos físicos da paisagem. Sant `anna Neto (2014, p.38) enfatiza que "a perspectiva teórica proposta pela Geografia do Clima é uma possibilidade de interpretação, de ir além da estrutura aparente da relação sociedade/ natureza, para um rompimento com o dualismo ou dicotomia entre o natural e o social, para os que consideram que a Geografia é uma ciência humana e que o fenômeno climático não deve ser encarado apenas como um processo físico e espacial".

Assim, torna-se possível dar uma resposta concreta à situação de vulnerabilidade à materialização de desastres em que se encontra grande parte da humanidade e do meio ambiente.

0 fazer geográfico com os estudantes: representação tridimensional da área de risco

Nos Parâmetros Curriculares Nacionais na área de Geografia (1998, p.41) constam os objetivos gerais da área na construção de um conjunto de conhecimentos referentes a conceitos, procedimentos e atitudes. Dentre eles, destaca-se "conhecer o mundo atual em sua diversidade, favorecendo a compreensão de como as paisagens, os lugares e os territórios se constroem [...]" .

Dessa forma, procura-se refletir sobre ações que potencializam os impactos negativos no espaço estudado, elege-se a paisagem como unidade espacial para análise, englobando singularidade histórica econômica e cultural. Na perspectiva da "fisiologia da paisagem" de Conti (2001, p.71).

\section{“[...] a Geografia tem por objeto próprio a compreensão do processo interativo entre sociedade e natureza, produzindo, como resul- tado, um sistema de relações e de arranjos espaciais que se expressam por unidades paisagísticas identificáveis. Esse enunciado, por si só, aponta para a dimensão e o enorme alcance de seu conteúdo, enquanto análise integrada de duas categorias indissociáveis: o espaço terrestre e a transformação nele operada pela atividade humana ao longo do tempo histórico".}

Assim, prosseguiu o estudo retratando o espaço com os aspectos naturais e humanos nele sedimentados, considerando o processo dinâmico e a totalidade. Enfim, a materialização do "sistema de objetos" sobrepondose na natureza onde o "sistema de ações" se exerce, condicionando novos objetos.

Experiência vivenciada por acadêmicos, alunos, professores da rede pública de ensino no Curso de graduação em Geografia na cidade de Aquidauana-MS/ Brasil, buscou identificar os aspectos que desvendam no espaço os atributos elencados por Santos (1978, p.80): 
"O espaço deve ser considerado como uma totalidade, a exemplo da própria sociedade que the dá vida [...] o espaço deve ser considerado como um conjunto de funções e formas que se apresentam por processos do passado $e$ do presente [...] o espaço se define como um conjunto de formas representativas de relações sociais do passado e do presente e por uma estrutura representada por relações sociais que se manifestam através de processos e funções".

De acordo com os Parâmetros Curriculares Nacionais (1998, p.40), do terceiro e quarto ciclos do ensino fundamental

\section{"[...] é fundamental que o espaço vivido pelos alunos continue sendo o ponto de partida dos estudos. A compreensão de como a realidade local relaciona-se com o contexto global é um trabalho a ser desenvolvido durante toda a escolaridade, de modo cada vez mais abrangente, desde os ciclos iniciais"}

Assim, num primeiro momento os acadêmicos fizeram um reconhecimento, reflexão sobre o espaço vulnerável ao risco, tendo o lugar e a paisagem como alvos de estudo, reconhecendo o lugar de vivência cotidiana como fração de uma empatia espacial coletiva. Inerente a isso está a paisagem, revelando intercursos das relações no tempo e no espaço, na sua essência objetos naturais e sociais dinâmicos de acordo com a evolução da sociedade.
Afirmaram que: "conscientizei com a minha profissão... a necessidade de busca constante na atuação do professor..... partir da realidade local".

“.... sinto que preciso dar estrutura para o meu aluno... provocar indagações.....auxiliar a desvendar o meio ...ir além do que se vê ou escuta."

Posteriormente, através de ações coletivas entre professores, alunos e acadêmicos o espaço foi reconhecido, observando-se a sua totalidade, a formação sócio espacial na perspectiva de compreender as singularidades da sociedade e do espaço.

De acordo com Santos, o espaço "reproduz a totalidade social na medida em que essas transformações são determinadas por necessidades sociais, econômicas e políticas. Assim, o espaço reproduz-se, ele mesmo, no interior da totalidade, quando evolui em função do modo de produção e de seus momentos sucessivos. Mas o espaço influencia também a evolução de outras estruturas e, por isso, torna-se um componente fundamental da totalidade social e de seus movimentos" (Santos, 2005, p.85).

Um aluno enfatizou: "Descobri que sou capaz de construir meu próprio conhecimento sobre o conteúdo que ensina. Entendi a utilização da Geografia. Compreendi como é usado esse lugar... a enchente... os prejuízos." Outro aluno informou: “... andar aqui me contou mais que meu livro..." Ainda foi ressaltado: "observo a extensão do manancial de água que serve a cidade... de onde ele vem...penso no que fazem nele por aí".
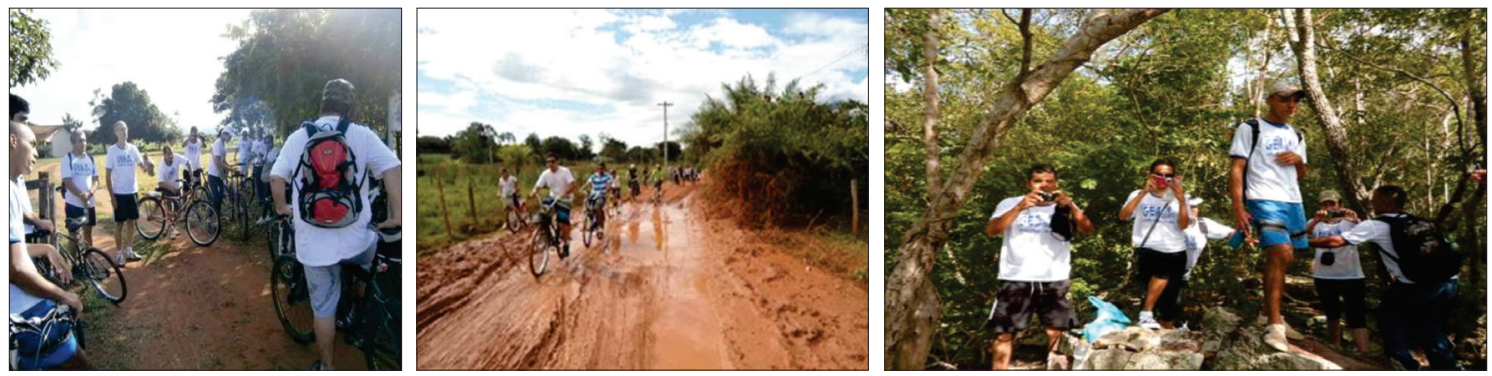

Fot. 1 - Acadêmicos conhecendo o chão (Fonte: Arquivo pessoal, maio de 2015).

Photo 1 - Academics getting to know the area (Source: Personal Archive, May of 2015).
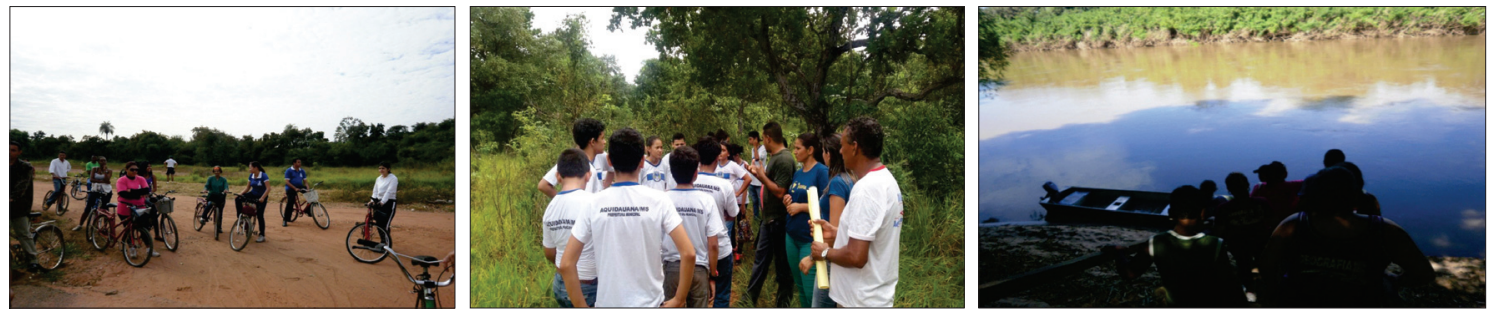

Fot. 2 - Reconhecimento da área (Fonte: Arquivo pessoal, maio de 2015).

Photo 2 - Recognition of the area (Source: Personal archive, May of 2015). 
Dessa forma, alunos, acadêmicos e professores observaram como o espaço é construído e reconstruído, como é ocupado e usado, sua função, o seu cotidiano, como os atores sociais o produzem. Realizaram uma descrição das características que desvendam a essência da vida do e no lugar.

Foi notória a concretização do processo de descoberta uma vez que suscitou a reflexão dos acadêmicos, dos alunos e professores na produção do conhecimento além de livros, sala de aula, desvendando questões obscuras, muito acima do que se vê e ouve. 0 grupo adentrou o espaço, apropriando-se dos aspectos social, físico, histórico, geográfico resultante de interações múltiplas no tempo e no espaço, libertando-se de prejulgamentos e preconceitos.

Os professores da escola onde o projeto foi desenvolvido afirmaram que: "Ao trabalhar em sala de aula quais foram, são e serão os construtores do espaço geográfico, (os alunos) polemizaram diversas opiniões e enfrentamento de posições.... aí trabalhamos conceitos, atitudes e valores".

"Ao instigar os alunos a estudar dentro e fora da sala de aula sobre os sujeitos construtores do espaço geográfico realizamos inconscientemente uma leitura do mundo... originou uma nova forma de pensar e questionar os fatos, duvidando, contrapondo e posicionando criticamente... a aprendizagem com o projeto foi significativa".

“Na escola a inovação no trabalho traz medo e insegurança, mas sem ela não é possível realizar um ensino de qualidade que transforme o saber dos alunos. 0 projeto alcançou o objetivo e demonstrou que a utilização de novas metodologias traz motivação aos alunos como também para professores. A busca de metodologias práticas de ensino e de aprendizagem facilita a relação entre professores e alunos. É muito produtivo partir do local de convivência e entender a sua história."

Constata-se nas falas dos professores saberes da experiência. Segundo Tardif (2002, p.56) estes saberes “[...] fornecem aos professores certezas relativas a seu contexto de trabalho na escola de modo a facilitar sua integração".

Neste projeto, destacam-se os professores como indivíduos ativos no processo de construção dos saberes. A difusão e a transferência de experiências acumularam um volume vasto de saberes nestes sujeitos, o que suscitará inovações e investidas profissionais.

Vlach et al. (2002) ressaltam que é preciso que os profissionais experimentem novos procedimentos de ensino atrelados as às necessidades concretas dos alunos, para que se possa produzir saberes reais.

Foi identificada uma troca de saberes através de observação, registro, cotejamento de falas de diferentes visões e abstração do espaço através de múltiplas ações complexas e combinadas na silmuntaneidade de olhares, experiências, reflexões na atuação orientada no propósito de compreender os riscos no uso e na ocupação de um dado espaço.

Esses episódios de desastre nos remetem a refletir as diferentes maneiras de visualizar ou de perceber o que vem a ser um risco. De acordo com Lourenço (2006), os riscos podem ser agrupados quanto à sua origem em: naturais - cujo dano tem a sua origem na natureza; antrópicos quando o fenômeno causador do dano tem origem em ações humanas; e mistos - quando o prejuízo apresenta causas combinadas (condições naturais e ações antrópicas).

Tratando-se de inundações, Rebelo (2001) classificaas como riscos de origem natural e hidrológicos. Os riscos hidrológicos estão por norma associados à água proveniente da precipitação e são, para a maioria dos autores, de cheia, de inundação e de alagamento, de acordo com Lourenço (2006).

Assim ao analisar a terceira dimensão do referido espaço a partir do mapa, o relevo representado através da altimetria ganhou um potencial significado. 0 grupo participante da atividade visualizou as formas topográficas na área de risco, indo de forma concreta do natural ao social e às ocorrências das águas que ensinam.

A base cartográfica que orientou o trabalho deu-se através da utilização do mapa cadastral planialtimétrico da planície de inundação da cidade de Aquidauana na escala de 1:10.000 e foi reeditado para a a escala 1:2.000 para obter mais detalhes planialtimétricos quando da construção da maquete e a metodologia utilizada foi de acordo com Anunciação e Sant `Anna Neto (2014).

Para a representação geomorfológica da área (fig. 2), foram retiradas as curvas de nível por classes de valores equidistantes de $1 \mathrm{~m}$ em $1 \mathrm{~m}$ de altitude em virtude da baixa altimetria, que apresenta variabilidade entre $136,00 \mathrm{~m}$ a $143,00 \mathrm{~m}$, o que torna a área estudada extremamente plana. Numa segunda fase, foi realizada a transposição individual das curvas de nível para as placas de poliestireno expandido (isopor) de acordo com a equidistância. Para desenhar o traçado das curvas no isopor, foi intercalado entre este e o mapa com a curva uma folha de papel carbono, passando sob o contorno a caneta, deixando-a demarcada na placa.

Para recortar as curvas, foi utilizado cortador de isopor e, em seguida, realizou-se a sobreposição e colagem das placas, iniciando-se pela cota mais baixa. Para dar a ideia da continuidade do relevo, os intervalos entre as diferenças de degraus das placas foram preenchidos com massa corrida, unindo a borda do degrau superior ao inferior na base. Após a secagem completa do material de recobrimento, foi utilizada lixa d'água, suavemente, para dar uniformidade ao acabamento e a pintura foi realizada com tinta a base de água (fot. 3 ). 


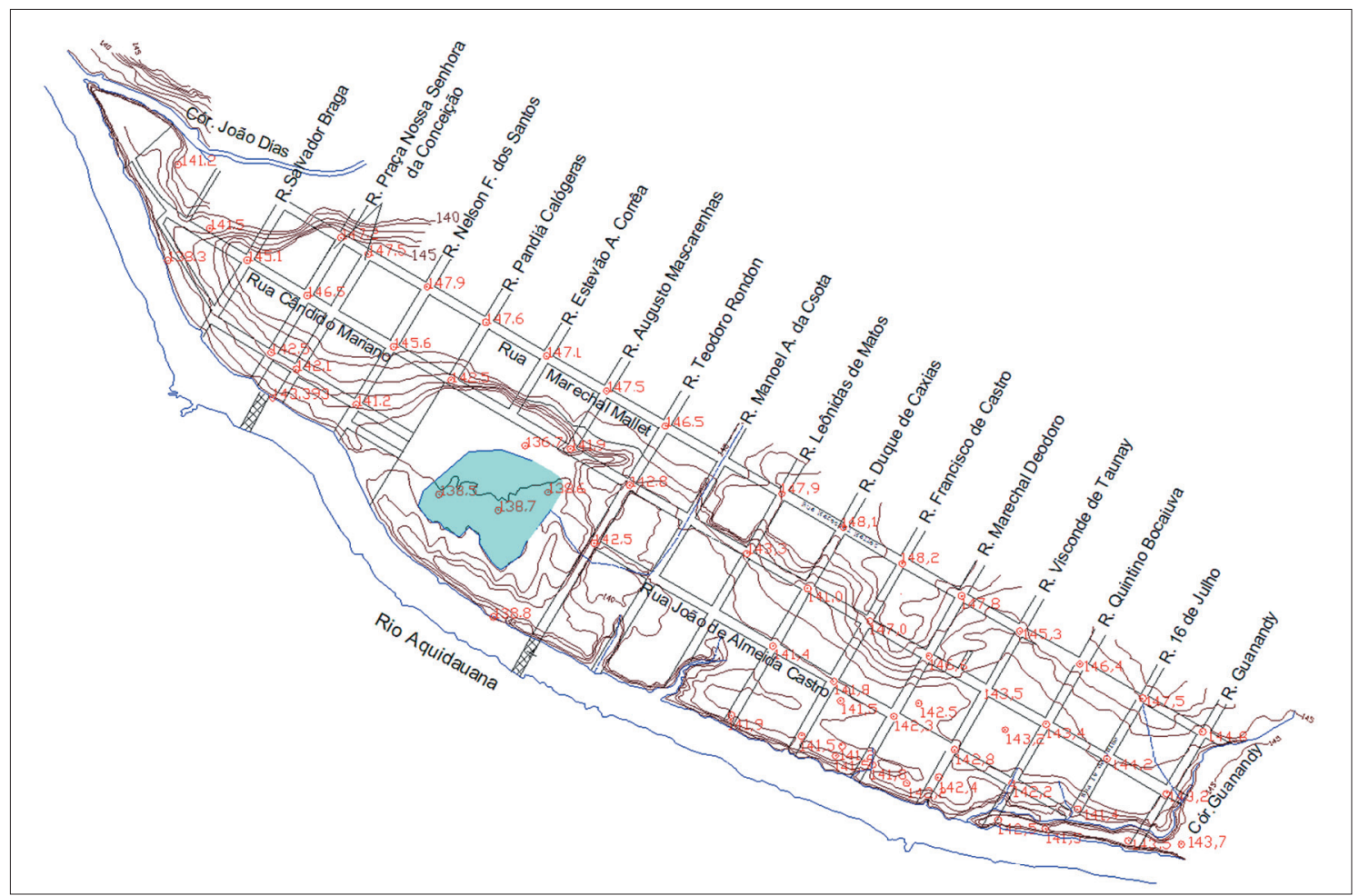

Fig. 2 - Cotas altimétricas da área de risco da cidade de Aquidauana (Fonte: Laboratório de Topografia e Cartografia, UFMS/CPAQ 2015).

Fig. 2 - Elevations of the risk area in the city of Aquidauana (Source: Topography and Cartography Laboratory,UFMS CPAQ 2015. ).
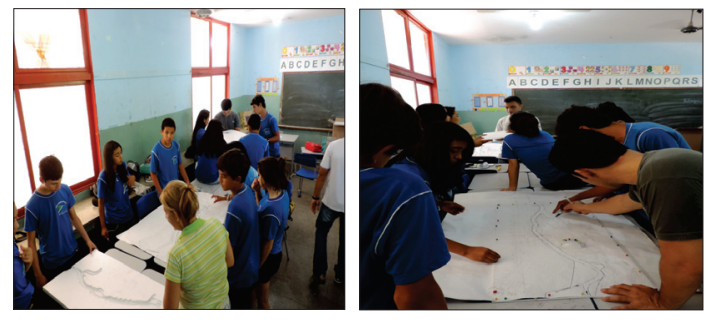

Fot. 3 - Construção da maquete da área de risco na cidade de Aquidauana.

Photo 3 - Construction of the scale model of the risk area in the city of Aquidauana.

Observa-se a consolidação cultural individual de cada agente social envolvido no processo, numa busca insistente pela compreensão da dinâmica do espaço. Resultados que não se encontram em laboratórios, na universidade, na escola. Foge, desvincula-se dos propósitos, da compatibilidade, da teoria, dos dados, desafiando até mesmo a consistente conclusão obtida através de pesquisa nessas fontes. Concretiza-se um conjunto de valores fortificados e atentos com a realidade local, uma postura de troca de saberes com o povo, enfim.... espaço..... este é a mensagem evidentemente.

Para Castellar et al. (2010), ensinar a ler em Geografia significa criar condições para que o aluno leia o espaço vivido a partir da linguagem cartográfica, efetivando-se o letramento geográfico. As autoras ressaltam que ao aproximar-se da leitura, o aluno consegue interpretar os
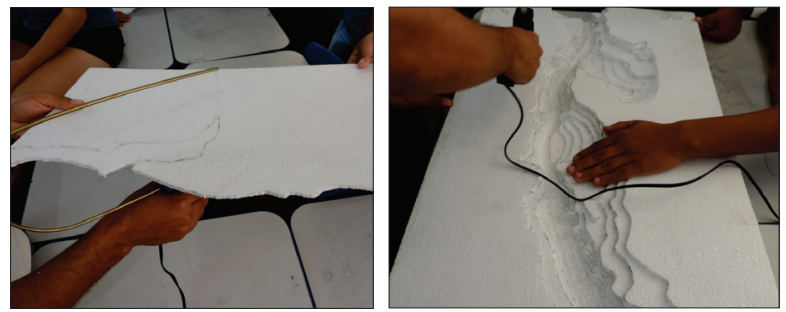

conceitos contidos no mapa relacionando com o espaço real a partir de seu espaço vivido, concretizando o respectivo processo de alfabetização geográfica.

Instigou a compreensão dos participantes como sujeitos ativos, percebendo sua inserção nos diferentes espaços, possibilitando reivindicações de prioridades essenciais na implementação das políticas públicas, fator de preservação da ética humana e de coesão social com o ambiente de vivência cotidiana, entendendo, com Santos (1985,p.75),

"O espaço, considerado como um mosaico de elementos de diferentes eras sintetiza de um lado a evolução da sociedade e explica, de outro lado, situações que se apresentam na atualidade. [...] a noção de espaço é assim inseparável da ideia de sistemas de tempo". 
As reflexões revelaram evidências do uso inadequado do solo urbano na "Zona Ribeirinha", por meio da manifestação de problemas advindos de eventos climáticos extremos, associados à compartimentação morfológica e pedológica da área, além da ineficácia de infraestrutura e equipamentos urbanos. A expansão territorial urbana, o planejamento ineficiente e as intervenções, sobretudo a partir da década de 1950, estiveram em descompasso com o desenvolvimento local.

Assim, utilizando-se a maquete como recurso didático, buscou-se desvendar a participação dos diversos atores sociais na gestão dos recursos hídricos, visando à promoção de soluções aos problemas socioambientais de forma interativa e coletiva.

Através do trabalho colaborativo/interdisciplinar, aproximaram-se a Universidade, a escola e comunidades envolventes no desvelamento de temáticas relacionadas ao processo de gestão dos recursos hídricos, sensibilizando-os pelas problemáticas socioambientais do regional ao local e, inerente a isso, despertou-se o sentimento de pertencimento ao lugar de vivência cotidiana. Além disso, foram deflagradas reflexões sobre a importância da água para todas as formas de vida e a necessidade de cooperação entre os municípios envolvidos na área da bacia, visando à conservação dos recursos hídricos.

\section{Conclusão}

A partir da imersão na experiência vivida e troca de saberes associados à geografia escolar e à climatologia geográfica, foram disponibilizados e proporcionados, a professores e alunos das instituições envolvidas, refereciais, conhecimento e habilidades teóricas e práticas, potencializando uma formação dupla em sua essência: constituição de sujeito ativo, crítico e aprimoramento na organização do estado da arte de pensar desse sujeito bem como de posicionar-se e interferir na construção do conhecimento.

Observou-se a consolidação da cultura individual de cada agente social envolvido no processo, numa busca insistente na compreensão da dinâmica do espaço. Sabese que o resultado é em longo prazo, mas gradativamente as formas de pensar, os hábitos vão sendo mudados e os alunos tornar-se-ão multiplicadores na sociedade de atitudes e ações que podem reverter os problemas/ prejuízos. Fixar um circuito integrado, operacional, de processamento, de armazenamento, de recebimento e emissão de conhecimentos e valores na espécie humana, em tempo real, é uma tarefa impossível! Mas com trabalhos dessa natureza, de modo lento e gradual, os anseios podem tornar-se possíveis!

São necessárias mudanças substantivas no quadro institucional universidade-escola. A universidade deve avançar além da condensação de grupos em algumas especificidades, temas, e conjugar de fato pesquisa e ensino. Não estar apenas com práticas amadorísticas de métodos e procedimentos complexos originando resultados inexpressivos de cunho científico. Mas vincular-se a disciplina Geografia no ensino básico, superando o distanciamento em relação aos problemas práticos vividos e à percepção imaginada e teórica da universidade sobre o ensino. Associar cada vez mais o caráter teórico e prático das pesquisas em educação geográfica e superar a dicotomia de trabalho entre universidade e escola, promovendo uma integração entre as diversas instituições com funções sociais afins, produtoras e consumidoras de informação e conhecimento. Além de contribuir com a oportunidade de desacorrentar a rotina que aprisiona o corpo e a mente e estreita os horizontes pessoais de professores universitários com projetos de pesquisa excessivamente individualizados, apresentando descontinuidade na produção e nenhuma influência na educação geográfica no ensino básico.

As ações conjuntas da escola, da universidade, dos alunos e dos professores, exigem um período determinado de maturação e são fruto de relações sociais concretas e verdadeiras, na em medida que vão sendo socializadas, disseminadas e apropriadas. Assim através do ensino e da aprendizagem, o momento histórico certo mostrará as mudanças e os resultados bem como a implementação de atores e gestores futuros, comprometidos com a lisura e honestidade na aplicação de recursos e minimização de impactos.

Então, para que universidade, escola, professores, gestores e alunos possam avançar no processo sem se contagiar com o surto da pós-modernidade: avalanches marqueteiro-midiáticas do inchaço do currículo, a valorização do papel da competitividade pela produtividade estatística quantitativa de publicações, mas dar uma resposta concreta à sociedade no que diz respeito à situação de penúria em que se encontra grande parcela da humanidade e o do meio ambiente, vulneráveis à materialização dos desastres.

Acreditar na potencialidade desses alunos para desenvolver ações futuras, alterar o quadro sombrio conhecido, é uma aposta de construção de saberes partindo do próprio espaço e incita-nos pagar para ver e com certeza vamos ganhar!

Além disso, para que as abordagens de métodos e técnicas sejam realizadas em consonância com as dimensões, a diversidade, as formas, e a dinâmica dos diversos componentes do espaço estudado, em interação social com o entremeado de diálogos, ações e compromissos, para que os docentes desenvolvam procedimentos metodológicos e para que os alunos tenham a possibilidade de pensar numa análise espacial, a partir da compreensão do lugar onde mora, dada à importância da aproximação do conhecimento com os lugares. 
Estudando a geografia do espaço, os alunos aprendem a ler, escrever e refletir. Isto exige que o professor esteja em sintonia constante com os problemas e as temáticas abordadas pela disciplina Geografia, além de ter ousadia no planejamento didático. Estes recursos são indispensáveis para instigar a aflição dos alunos diante dos fatos, promover a busca incessante de conhecimento, amplificando a compilação de fontes literárias para leitura e redação.

O desenvolvimento deste estudo oportunizou o tratamento de questões sociais, naturais e educacionais numa abordagem íntegra, proporcionando aos acadêmicos formação inicial e estimulando a busca de capacitação para alternativas de atuação profissional no âmbito da análise ambiental na perspectiva do ensino da educação básica como em trabalhos interdisciplinares de planejamento e gestão, sobretudo dos recursos hídricos. Além disso, valoriza-se a socialização do conhecimento e das informações com a comunidade local, permitindo que se aproprie dos saberes, podendo utilizá-los como ferramenta para requerer ou agir em intervenções que se fizerem necessárias.

Assim, é possível disponibilizar a informação e o conhecimento a serviço da sociedade. Como dizia Freire (1996, p. 80), "o fato de me perceber no mundo, com o mundo e com os outros me põe numa posição em face do mundo que não é de quem nada tem a ver com ele".

\section{Referências bibliográficas}

Anunciação, V. S. da; Sant 'Anna Neto, J. L. (2014). Prevenção de riscos com a comunidade local na planície de inundação do rio Aquidauana na cidade de Aquidauana MS/Brasil. In: RISCOS - Associação Portuguesa de Riscos, Prevenção e Segurança (Org. ). Multidimensão e territórios de risco, Coimbra; p. 887-891. Disponível em: https://digitalis.uc.pt/ pt-pt/livro/preven\%C3\%A7\%C3\%A3o_de_riscos_ com_comunidade_local_na_plan\%C3\%ADcie_de_ inunda\%C3\%A7\%C3\%A3o_do_rio_aqiuidauana_na_ cidade.

BRASIL (1998). Secretaria de Educação Fundamental. Parâmetros curriculares nacionais: geografia / Secretaria de Educação Fundamental. Brasília: MEC/SEF.

Callai, H. C. (2003). O Ensino de Geografia: Recortes Espaciais para Análise. In: Castrogiovanl, Carlos [et al.]. (orgs). Geografia em Sala de Aula: Práticas e Reflexões. 4. ed. Porto Alegre: Editora da UFRGS.

Castellar, S. (2010). Ensino de Geografia. São Paulo: Cengage Learning.

Conti, J. B. (2001). Resgatando a fisiologia da paisagem. Revista do Departamento de Geografia da USP, n. 14., P. 59-68.
Freire, P. (1996). Pedagogia da autonomia: saberes necessários à prática educativa. Rio de Janeiro, Paz e Terra.

Kaercher, N. A. (2003). A Geografia é o Nosso Dia-a-dia. In: Castrogiovani, Carlos [et al.]. (orgs). Geografia em Sala de Aula: Práticas e Reflexões. 4. ed. Porto Alegre: Editora da UFRGS.

Lourenço, L. (2014). Risco, Perigo e Crise. Trilogia de base na definição de um modelo conceptual operacional. In Realidades e desafios na gestão dos riscos - Diálogo entre ciência e utilizadores, 61 - 72. Coimbra: NICIF - Núcleo de Investigação Científica de Incêndios Florestais. Disponível em: https://digitalis. uc.pt/ptpt/livro/risco_perigo_e_crise_trilogia_de_ base_na_defini\%C3\%A7\%C3\%A3o_de_um_modelo_ conceptual_operacional. Acesso em: 10 de jan. 2017.

Lourenço, L. (2006). Riscos naturais, antrópicos e mistos. Territorium, 14, Coimbra, p.109-113. Disponível em: http://impactum-journals.uc.pt/territorium / article/view/3266/2513.

Lourenço, Luciano (1999). Coimbra e os riscos naturais. Passado e presente. Caderno de Geografia e Actas do I Colóquio de Geografia em Coimbra, $n^{\circ}$ especial, p.37-43. Disponível em: https://www.uc.pt/fluc/ nicif/Publicacoes/Estudos_de_Colaboradores/PDF/ Comunicacoes_congressos/IColoquio_de_Geografia_ de_Coimbra_1996.

Nunes, A, Lourenço, L., Pinho, J, Bento-Gonçalves, A. e Vieira, A. (2013). Episódios Hidrometeorológicos Extremos Noticiados no Distrito de Coimbra Durante a Segunda Metade do Século XIX. Territorium, Revista da Associação Portuguesa de Riscos, Prevenção e Segurança, $n^{\circ} 20$, p 29-36. Disponível em: http://www.uc.pt/fluc/nicif/riscos/Documentacao/ Territorium/T20_artigos/T20_Artigo03.pdf.

Rebelo, F. (1997). Riscos e a crise nas inundações rápidas em espaço urbano. Alguns exemplos portugueses analisados a diferentes escalas. Territorium, Revista da Associação Portuguesa de Riscos, Prevenção $e$ Segurança, 4, p. 29-27. Disponível em: http://www. uc.pt/fluc/nicif/ riscos/Documentacao/Territorium/ T04_artg/ T04_Artg04.pdf.

Rebelo, F. (2003). Riscos Naturais e Acção Antrópica. Estudos e Reflexões. Coimbra, Imprensa da Universidade, 286 p. ( $2^{\text {a }}$ edição, revista e aumentada). Disponível em: https://digitalis.uc.pt/ pt-pt/livro/riscos_naturais_e_ac\%C3\%A7\%C3\%A3o_ antr\%C3\%B3pica_estudos_e_reflex\%C3\%B5es.

Rebelo, F. (2010). Geografia física e riscos naturais. Coimbra: Imprensa da Univ. de Coimbra, 215 p.

Sant `anna Neto, J. L. S. (2008). Da climatologia geográfica à geografia do clima: gênese, paradigmas 
e aplicações do clima como fenômeno geográfico. Revista da Anpege, 4. São Paulo.

Sant anna Neto,J.L.S.(2014). Climatologia e geografia em dez questões. Disponível em: http://www.abclima.ggf.br.

Santos, M. (1978). Por uma Geografia Nova. São Paulo: Hucitec, Edusp.

Santos, M. (1979). Espaço e Sociedade. Petrópolis: Vozes.

Santos, M. (1985). Espaço e método. São Paulo: Nobel.

Santos, M. (2005). Da totalidade ao lugar. São Paulo, EDUSP.

Seabra, O. C. L. (2001). Urbanização e fragmentação: apontamentos para o estudo do bairro e da memória urbana. In: Sposito, M. E. B. (Org.) Urbanização e cidades: perspectivas geográficas. Presidente Prudente: UNESP / GASPERR, p. 75-96.

Tripp, D. (2005). Pesquisa-ação: uma introdução metodológica. Educação e Pesquisa, São Paulo, v. 31, n. 3, p. 443-466, set./dez.

Tardif, M. (2007). Saberes Docentes e Formação Profissional (8a Ed. ed.). Petrópolis: Editora Vozes.

Vlach, V. R. (2002). Geografia escolar: relações e representações da prática social. Revista Caminhos da Geografia 3(5), Fev/ Instituto de Geografia UFU, 2002. p. 44-51. Disponível em: http://www.seer. ufu.br/index.php/caminhosdegeografia/article/ view/10103/5972. 